\title{
Part and parcel of eliding partitives*
}

\author{
Michaël R. Gagnon \\ University of Maryland
}

\begin{abstract}
This paper argues that bare determiners, as in the sentence Many sat down, should be analyzed as involving the elision of a partitive phrase, as opposed to a noun phrase, as is commonly assumed (Lobeck 1991, 1995; Bernstein 1993; Panagiotidis 2003; Alexiadou \& Gengel 2011; Corver and van Koppen 2009, 2011). This analysis is supported by: (i) the anaphoric interpretation of the bare determiners in context; (ii) the syntax of bare determiners; and (iii) deep event anaphora. Further, the adoption of partitive ellipsis comes with the suggestion that partitive DPs do not involve null intermediary noun phrases (cf. Jackendoff 1977, Sauerland and Yatsushiro 2004, and Ionin, Matushansky \& Ruys 2006), but rather that determiners can take partitive phrases as internal arguments (Matthewson 2001). The existence of such a phenomenon also militates in favor of a meaning isomorphy approach to the licensing of ellipsis (Merchant 2001), rather than structural isomorphy (Fiengo \& May 1994).
\end{abstract}

Keywords: ellipsis, noun phrase ellipsis, anaphora, pronouns, partitives, event anaphora

\section{Partitive ellipsis}

It is commonly assumed ${ }^{1}$ that cases of bare determiners in languages like English (1a) and French (1b) involve the ellipsis of a noun phrase (NPE).

(1) a. Ten boys walked in the room. Many boys sat down.

b. Dix garçons sont entrés dans la pièce.

Plusieurs garȩens se sont assis.

Here, I will argue that such constructions involve the ellipsis of a partitive phrase containing a plural anaphoric pronoun (PartE), as in (2).

* I am grateful to Alexander Williams, Valentine Hacquard, Matthew Barros, Lucas Champollion, Marcel den Dikken, Karen Duek, Norbert Hornstein, Dave Kush, Brad Larson, Howard Lasnik, Kyle Rawlins, Uli Sauerland, Philippe Schlenker, Greg Scontras, Roger Schwarzschild, Alexis Wellwood, as well as the audiences at the CUNY supper talks, the UMD Syntax-Semantics Lab, and the Third MACSIM, for comments and discussion on this work. Any and all errors are mine, indubitably.

1 Lobeck 1991, 1995; Bernstein 1993; Panagiotidis 2003; Alexiadou \& Gengel 2011; Corver \& van Koppen 2009, 2011.

C)2013 Gagnon 
Part and parcel of eliding partitives

(2) a. Ten boys walked in the room.

Many of them sat down.

b. Dix garçons sont entrés dans la pièce.

Plusieurs d'entre eux se sont assis.

I further propose that this partitive phrase is directly taken as an internal argument by the determiner. To achieve this semantically, I assume the partitive phrase to be of type $\langle e, t\rangle$, and to encode proper partitivity, as suggested by Barker (1998):
a. $\llbracket \mathrm{of} \rrbracket=\lambda x . \lambda y \cdot y<x$
b. $\llbracket$ of them $1 \rrbracket^{g}=\lambda y \cdot y<g(1)$

I present evidence for this approach from the interpretation of anaphora in $\S 2$, evidence from syntax in $\$ 3$, and evidence from deep event anaphora in $\$ 4$. Then, in $\S 5$, I discuss the underlying structure of partitives. In $\S 6$ and $\S 7$, I discuss issues with mass partitives, and other apparent types of ellipsis, which could be taken to challenge the current proposal. Finally, I broach the topic of ellipsis licensing in $\S 8$ and conclude briefly in $\S 9$.

\section{Evidence from anaphora}

Examples such as (1) and (2) above cannot distinguish between the NPE approach and the PartE approach, on the account that a single discourse referent is available in context. Assuming that an elided phrase obtains the same interpretation as its overt counterpart (call this assumption meaning parity), the NPE and PartE approaches make the same predictions with respect to anaphoric readings in such simple contexts.

However, the interpretation of ellipsis in more complex contexts, involving a plurality of discourse referents, supports the PartE analysis and is incompatible with the NPE analysis.

To see this, consider the discourse segment in (4). There, three different reference sets are introduced, corresponding to the boyscouts already present in class $(\mathbf{X})$, the girlscouts $(\mathbf{Y})$, and the ten boys who later walked in $(\mathbf{Z})$.

(4) a. I arrived in class five minutes before the start.

There were boyscouts $(\mathbf{X})$ and girlscouts( $(\mathbf{Y})$ standing at their desks.

Then, ten young boys $(\mathbf{Z})$ walked in whistling.

b. [Many _ _ ] sat down.

Can mean [Many Z], or [Many $X \cup Y \cup Z$ ]

Cannot mean [Many $X \cup Z$ ]

c. $=[$ Many of them $]$ sat down.

Can mean [Many Z], or [Many $X \cup Y \cup Z$ ]

Cannot mean [Many $X \cup Z$ ] 


\section{d. $\neq$ Many boys sat down.}

\section{Can only mean [Many $X \cup Z]$}

Considering (4b), we see that the readings available for the ellipsis site, the sets restricting the quantifier in context, are just those available for an overt partitive phrase containing a plural anaphoric pronoun, as in (4c) - namely, the most salient reference set, consisting of the young boys who just walked in $(\mathbf{Z})$, or the set of all individuals available in context $(\mathbf{X} \cup \mathbf{Y} \cup \mathbf{Z})$. Crucially, these readings are distinct from that of the sentence involving the overt NP 'boys', in (4d), which leads to quantification over the boys present in the context $(\mathbf{X} \cup \mathbf{Z})$. Following the meaning parity assumption, PartE makes the correct predictions here, whereas NPE does not.

Further, to support the claim that PartE involves an embedded plural pronoun, note that the 'anaphoric reach' of the ellipsis site in such cases is the same as that of a simple anaphoric plural pronoun:

a. I arrived in class five minutes before the start.

There were boyscouts $(\mathbf{X})$ and girlscouts $(\mathbf{Y})$ standing at their desks.

Then, ten young boys $(\mathbf{Z})$ walked in whistling.

b. [They] sat down.

Can refer to [Z], or $[X \cup Y \cup Z]$

Cannot refer to $[X \cup Z]$

Here, the plural pronoun can refer back to the sets quantified over by the bare determiner in (4) above. Again, it crucially cannot refer to the set of individuals picked out by the NP 'boys' in this context.

Cases of ellipsis in donkey constructions with split antecedents also militate in favor of the PartE approach over the NPE approach:

a. If a man has a wife who owns a donkey, he surely likes [one (of them/*wife and/or donkey)] better.

b. If a man has a wife who owns a donkey, he likes [the two (of them/*wife and donkey)] equally. ${ }^{2}$

In (6), only an overt partitive phrase would be acceptable in the ellipsis site, and yield the desired reading in context. ${ }^{3}$ There are no noun phrases which would be appropriate in this context.

I conclude here that evidence from anaphora strongly supports the PartE approach, and is incompatible with the common NPE view.

2 In such cases, using the type of copy mechanism proposed for NPE in Elbourne 2005, based on Fiengo \& May 1994, would not yield the desired result.

3 I am grateful to Philippe Schlenker for pointing out such cases. 
Part and parcel of eliding partitives

\section{Evidence from syntax}

Support in favor of the PartE approach can also be found in the syntactic distribution of the determiners allowing ellipsis in their scope (or c-command domain). This section discusses different types of evidence from English and French.

\subsection{Ellipsis licensing determiners (ELDs)}

In English, there is a split between Determiners which license ellipsis in their scope and those which do not: ${ }^{4}$

(7) A group of boys walked in the room.

a. $E L D$

[Most/Each/Some/One/All/Many/Few/Both _ ] sat down.

b. Non-ELD

*[Every/The/A/No _ _ ] sat down.

Under an NPE approach, it is unclear what could account for this arbitrary distinction. Why could a noun phrase be elided following the determiners in (7a), but not those in (7b)? The PartE approach, on the other hand, predicts this generalization. The determiners in (7a) can take partitives, but not those in $(7 b)$ :

(8) a. [Most/Each/Some/One/All/Many/Few/Both (of them)] sat down.

b. * [Every/The/A/No (of them)] sat down.

If we assume that only partitive phrases can be elided, then we can straightforwardly account for this distribution.

\section{2 *Stranded adjectives}

Adding a prenominal modifier to all the licit examples of the paradigm renders them illicit:

(9) $*[$ Most/Each/Some/One/All/Many/Few/Both tall __ $]$ sat down.

Perhaps unsurprisingly, adding a modifier to the illicit ones leaves them illicit:

* [Every/The/A/No tall __ ] sat down.

4 See Jackendoff 1977 and Chomsky 1981 for early discussion of this generalization. 
All else being equal, the stranding of prenominal modifiers is what we would expect for cases of NPE. This is in fact what we find in French, as in (11), and German, as in (12). ${ }^{5}$

a. J'ai vu les garçons dans la cour. [Les grands _ ] jouaient I'have seen the boys in the courtyard. [The tall _ ] played avec [les petits _ ] with [the little _ ]

'I've seen the boys in the courtyard. The big ones were playing with the little ones.'

b. J'ai vu les garçons dans la cour. [Le grand _ ] jouait I'have seen the boys in the courtyard. [The tall _ ] played avec [le petit__ ]. with [the little _ ]

'I've seen the boys in the courtyard. The big one was playing with the little one.'

(12) Ich traf einige Studenten, und [die jungen _ _ ] wollen mit mir sprechen. I met some students, and [the young _ ] wanted with me to speak

'I met some students, and the young ones wanted to speak with me.' 6

I return to this cross-linguistic distinction in $\$ 3.3 .1$. This impossibility to strand adjectival modifiers in English can be further contrasted with the possibility to strand adjuncts:

(13) 10 boys walked in the room.
a. [Some [PartPof them] [from Swabia]] sat down.
b. [Some [PartP of them] [from Swabia]] sat down.
c. * [Some tall [PartPof them]] sat down.
d. * [Some tall [PartPof them]] sat down.

Here again, the PartE approach can help us get a grip on the English facts discussed so far. The adjuncts, which can be stranded under ellipsis, can co-occur with partitive phrases, as seen in $(13 \mathrm{a}, \mathrm{b})$. The adjectives, which cannot be stranded, simply cannot co-occur with partitive phrases, as shown in (13c,d).

Note that the modifiers stranded under ellipsis, such as relative clauses and prepositional phrases, can, and in some cases must, be attached higher in the DP than the partitive phrase. This is made obvious from the fact that these modifiers cannot 'move' with an extraposed partitive phrase (Jackendoff 1977: 109):

5 See for instance Lobeck 1995, and Sleeman 1996.

6 The French cases are originally from Herschensohn 1978; the German from Lobeck 1995. 
Part and parcel of eliding partitives
a. * Of the men that you met, $\left\{\begin{array}{l}\text { the group } \\ \text { the many }\end{array}\right\}$ aren't here anymore.
b. Of the men, $\left\{\begin{array}{l}\text { the group } \\ \text { the many }\end{array}\right\}$ that you met aren't here anymore.

Thus I take it that only phrases which can modify partitive phrases can be stranded under PartE. Another fact supporting the attachment of adjuncts to PartPs is that plural pronouns cannot combine with such adjuncts, and so in (15b), the modifier cannot be embedded in the PartP.
a. * [They from Swabia] sat down.
b. [Most of them from Swabia] sat down.

As an interim conclusion, I assume that apparent NPE, as in French and German, can strand adjectival modifiers; I further take the impossibility to strand adjectives as an indicator that no NPE has taken place. I will, however, present some evidence below, in $\$ 3.3 .1$, which sheds doubt on the idea that proper NPE even exists in languages such as French.

\subsection{Evidence from French}

French also exhibits PartE in constructions equivalent to the English ones discussed so far:

(16) Dix garçons sont entrés dans la classe. ten boys BE-AUX entered in the class

'Ten boys entered in the class.'

a. [Plusieurs__] se sont assis.

Many _ REFL-CL BE-AUX sit

'Many sat down.'

b. [Deux/Trois__ ] se sont assis.

Two/Three _ REFL-CL BE-AUX sit

'Two/Three sat down.'

As expected, all of these determiners can take an overt PartP:

(17) Dix garçons sont entrés dans la classe.

ten boys BE-AUX entered in the class

'Ten boys entered in the class.' 
a. [Plusieurs d' entre eux] se sont assis.

Many of among them REFL-CL BE-AUX sit

'Many of them sat down.'

b. [Deux/Trois d' entre eux] se sont assis.

Two/Three of among them REFL-CL BE-AUX sit

'Two/Three of them sat down.'

In fact, some determiners which allow ellipsis can only take a PartP argument, and not an NP argument:

a. [Peu d' entre eux] se sont assis.

Few of among them REFL-CL BE-AUX sit

'Few of them sat down.'

b. * [Peu garçons] se sont assis.

Few boys REFL-CL BE-AUX sit

'Few boys sat down.'

c. [La plupart d' entre eux] se sont assis.

The most of among them REFL-CL BE-AUX sit

'Most of them sat down.'

d. * [La plupart garçons] se sont assis.

The most boys REFL-CL BE-AUX sit

'Most boys sat down.'

It is then by necessity that in such cases a PartP, and not an NP, is elided.

We can also verify that the cases in (16) are interpreted as if a PartP containing a plural anaphoric pronoun were missing in complex contexts:

(19) a. Je suis arrivé en classe dix minutes avant le début.

I AUX-BE arrived in class ten minutes before the beginning

'I arrived in class ten minutes before the start.'

b. Il y avait des louveteaux et des jeannettes qui se

There it was some boyscouts and some girlscouts that SE-CL

tenaient derrière leurs pupitres.

stood behind their desks

'There were boyscouts and girlscouts standing behind their desks.'

c. Ensuite, dix jeunes garçons sont entrés en sifflant.

After, ten young boys AUX-BE entered while whistling

'Then, ten young boys entered whistling.' 
Part and parcel of eliding partitives

$$
\begin{aligned}
& \text { d. [Plusieurs _ ] se sont assis. } \\
& \text { [Many _ _ SE-CL AUX-BE sit } \\
& \text { 'Many sat down.' }
\end{aligned}
$$

Here, just as in the cases presented in English above, the interpretation of the ellipsis site is equivalent to that of an overt PartP containing a plural pronoun, and not to that of an overt NP.

\subsubsection{Another type of 'ellipsis' in French}

As mentioned, French seems to allow the stranding of adjectival modifiers. This fact appears to be compatible with a traditional treatment of these cases of ellipsis in terms of NPE. Here I will follow the previously made assumption that such cases are to be treated on par with English ONE-anaphora, as in (20b): ${ }^{7}$

\section{a. FRENCH}

J'ai vu les garçons dans la cour. [Les *(grands) __ ] jouaient avec [les *(petits) _ ]

\section{b. ENGLISH}

I saw the boys play in the yard. [The *(tall) ONES] played with [the *(small) ONES].

A peculiar fact about such constructions is that in both the English and French constructions, a modifier, typically adjectival, must be present (Halliday and Hasan 1976). This is also highlighted in (20).

I wish to suggest that, in the French cases, we are not faced with NPE either, but rather with a null anaphoric pro-noun, the equivalent of ONE in English. I dub this type of anaphora Contrastive Anaphora (ContrA). The decision not to treat these cases as involving NPE comes from the fact that the anaphoric reach of these expressions is the same as that of PartE in complex contexts (in English here, the same holds for French): ${ }^{8}$

(21) a. I arrived in class five minutes before the start.

There were boyscouts $(\mathbf{X})$ and girlscouts $(\mathbf{Y})$ standing at their desks.

Then, ten young boys $(\mathbf{Z})$ walked in whistling.

b. [The tall ONES] sat down.

Can refer to [the tall $Z s$ ], or [the tall $X \cup Y \cup Z s$ ]

Cannot refer to [the tall $X \cup Z \mathbf{s}$ ]

7 See Alexiadou \& Gengel 2011, and Corver \& van Koppen 2009, 2011 for recent proposals.

8 I am grateful to Uli Sauerland for bringing this fact to light. 
Here again, if we were faced with NPE, or $\mathrm{N}^{\prime}$-substitution, of boys, we would expect the anaphoric reference to be to all the boys present in the context. Yet this is not the reading we find.

For concreteness, I adopt here the syntactic analysis proposed by Corver \& van Koppen (2009) for a number of languages (Afrikaans, Frisian, Dutch, English French, etc.):

\section{UNDERLYING STRUCTURES:}

a. French: [DP Les [FocP grands [NumP [NP ONEs ] ] ]

b. English: [DP Many [FocP tall [NumP [NP ONES ] ] ] ]

In these constructions, the modifier is required to move in the focus phrase projection, where it supplies the basis for the contrast established. I further assume that the use of the overt or covert ONE is licensed by the presence of the focus projection.

\subsection{Distinguishing PartE from ContrA}

Support can be gleaned in French for my hypothesized distinction between PartE and ContrA. In this language, the presence of the partitive clitic en is required in cases of PartE.

a. J' en connaissais [trois/plusieurs/peu (d' entre eux)].

I EN-CL knew [three/many/few (of among them)]

b. Je connaissais [trois/plusieurs/peu *(?d' entre eux $)$.

I knew [three/many/few (of among them)]

In (23a), we see that the structure involving an overt or elided partitive in object position is compatible with the presence of the clitic. This contrasts with the cases in $(23 \mathrm{~b})$, where the clitic cannot be omitted in cases of PartE.

In opposition to PartE, the clitic cannot appear in cases of ContrA:
a. * J' en connaissais [les grands _ ] ].
I EN-CL knew [the tall__]
b. *Je/J'en connaissais [les grands d' entre eux].
I/I'EN-CL knew [the tall of among them]
c. Je connaissais [les grands $\Theta \mathrm{NE}]$.
I knew [the tall ones]

In (24a), we see that the clitic cannot co-occur with cases of ContrA, which is otherwise fully acceptable, (24b). I take this contrast to support the distinction I make between PartE and ContrA. 
Part and parcel of eliding partitives

Another contrast between PartE and ContrA pertains to the determiners found in the constructions. Specifically, definites (le/les) and indefinites (un/des) appear in the ContrA constructions, but do not allow for PartE, as seen above for English in $\S 3$.

\section{Evidence from deep event anaphora}

Further evidence for PartE can be found in its interaction with deep anaphora (Hankamer and Sag 1976) and event anaphora.

It has been known for sometime that deep anaphora is generally possible in the cases I identify here as PartE: ${ }^{9}$

[Matt snatches an egg from Ian on stage, and smashes it on the floor]:

Matt: Don't worry folks, he has [several/many/more/some more _ ]

However, it is rather strange that deep anaphora to events is not equally possible. Consider (26a), involving PartE, which contrasts with the acceptable case in (26b), involving a singular anaphoric pronoun.

(26) [While looking at an arguing couple]:

a. * [Some/Most/All__ ] always happen(s) right after Valentine's day.

b. It always happens right after Valentine's day.

Under the PartE approach, this peculiarity can be explained by two things.

The first part of my explanation is the fact that plural pronouns cannot refer to implied events (Neale 1988):

(27) a. Psmith saw every student leave, but Maja didn't see it/\#them.

b. John talked and Mary danced. It/\#They took place in this room.

In both examples in (27), only singular pronouns can be used to make anaphoric reference to what is clearly understood as pluralities of events.

The second part of the explanation is the fact that the internal argument of partitives must have proper subparts (Barker 1998):

$$
\text { * Many of the boy }
$$

Under Barker's (1998) analysis, this is ensured by treating the partitive 'of' as encoding proper partitivity (cf. Ladusaw 1982):

9 This examples is taken from Chisholm 2002. 


$$
\llbracket \operatorname{of}_{P A R T} \rrbracket \equiv \lambda x . \lambda y \cdot[y<x]
$$

As a result of this denotation, the first argument of the partitive must have proper subparts; that is, it must either be plural or mass.

Putting the pieces together, we can now explain the impossibility of (deep) event anaphora under PartE. Given that anaphoric pronouns referring to implicit pluralities of events can only be singular, they cannot be embedded into a partitive, and so PartE cannot have an implicit event as its antecedent when combined with count partitives (Ionin, Matushansky \& Ruys 2006).

Under the NPE approach, the impossibility of cases like (26) is rather mysterious. Surely NPE could pragmatically resolve an event noun like argument, if it can resolve a concrete entity noun like egg in (25). It is very unclear to me what exactly this distinction could be attributed to under such an account. Without a resolution to this issue, I take it that the facts pertaining to deep event anaphora presented here support PartE over NPE.

\section{The structure of partitives}

So far, I have not been precise with respect to the syntactic structure I assume for partitive constructions. Two main views can be found in the literature. One assumes that a covert NP is always present, which is taken as internal argument by determiners, and takes the PartP as complement (Jackendoff 1977; Sauerland \& Yatsushiro 2004; Ionin, Matushansky \& Ruys 2011). The second assumes that determiners combine directly with the PartP, without the presence of an intervening null NP (Matthewson 2001). Here, I opt for the second view, and assume the structure in (30) in cases of PartE.

$$
\left[D P \text { Most [PartP of [DP the boys] ] ] (Matthewson 2001) }{ }^{10}\right.
$$

In essence, my suggestion is that certain determiners (those that can appear bare) can take either NPs or (partitive) PPs as arguments. This approach to determiners finds a parallel in the clausal domain in verbs like rob which select for specific PP arguments:

\section{(31) John robbed Mary of everything she had.}

The determiners that can combine directly with PartPs are to be contrasted with every, the, $a$ and no, which only take NP arguments in English.

My choice of this syntax is based on two reasons. First, the assumed covert noun cannot typically be overt:

10 Here, although I adopt the syntactic structure proposed by Matthewson, I do not adopt her treatment of the partitive of as semantically vacuous. 
Part and parcel of eliding partitives

* Most boys of the boys

Second, this structure can readily account for the ban on adjectival modifiers discussed above, given that such adjectives can only modify nouns, and not PartPs. ${ }^{11,12}$

* Most tall (of them) sat down.

The alternative to this approach would be to assume that a null NP is always present:

[DPMost [NP $\langle$ boys $\rangle$ [PartP of [DP the boys] ] ] ]

(Sauerland \& Yatsushiro 2005; Ionin, Matushansky \& Ruys 2011) ${ }^{13}$

Under this view, the null NP could then be the target of deletion, and perhaps fall under an NPE treatment. However, this would require an explanation of the impossibility of cases like (32) and (33). It would also fall short of explaining why all types of NPE are not generally possible. In other words, under this approach, cases of NPE would be required to have a PartP argument containing a plural anaphoric pronoun. I have little to say about this alternative, other than to point to the generalizations discussed above.

To summarize, even though PartPs appear to be combinable with both NPs and a subset of determiners, only PartPs can be elided, an not NPs with a partitive complement.

\section{Issues with mass partitives}

Here I wish to highlight a puzzle pertaining to mass partitives, which comes about under the PartE approach. First, note that mass partitives appear to be subject to PartE: ${ }^{14}$

George gave me wine, and..

11 For alternative views cast in X'-theory and HPSG see Jackendoff 1977 and Nerbonne, Iida and Ladusaw 1989.

12 Of course, I also allow for the possibility that partitive PPs can be complements to nouns (and combine through predicate modification):

(i) ? Armando only likes three books of the books I read.

13 See the appendix for a brief discussion of Ionin, Matushansky \& Ruys 2011.

14 However, as pointed out to me by Louise McNally, this might not always be the case. As follow up to (35), contrast the overt Most of it ended up spilled on the white tablecloth. with its elided counterpart ?Most ended up spilled on the white tablecloth. If this contrast is robust, then we would be required to distinguish the determiners allowing for the deletion of a mass partitive. At the moment, however, I am rather unclear on what could be the basis of this distinction. 
a. Some of it was spilled on the white tablecloth.

b. Some of it was spilled on the white tablecloth.

However, cases involving coercion of a count noun as a mass noun, the so-called universal grinder (Pelletier 1975: 5-6), cannot undergo ellipsis.

(36) The boys came back from playing outside.

a. Most of them were covered in mud.

b. Most of them were covered in mud.

(37) The boy came back from playing outside.

a. ? Most of him was covered in mud.

b. * Most $\theta$ him was covered in mud.

In (36), we have a typical case of PartE, where a partitive containing a plural pronoun is elided. In (37), we have a case involving a singular pronoun anaphoric to a count individual subsequently coerced as mass. There, the overt version in (37a), although degraded, contrasts sharply with its elided counterpart in (37b), which is clearly unacceptable.

The same contrast holds of partitives containing an event-referring pronoun:

(38) James danced himself to death.

a. ? Still, most of it was enjoyable.

b. * Still, most of it was enjoyable.

This is rather puzzling. It appears that an overt expression must be present for the universal grinder or event reference to take place. Perhaps the type of coercion involved in turning count expressions into mass meanings is similar in nature to what is involved in making anaphoric reference to implied events. But I can offer little more than speculations here, and hope that future work will shed light on this issue.

\section{Other apparent types of ellipsis}

To the best of my knowledge, there are in English two other apparent types of ellipsis which do not readily fall under PartE or ContrA. The first, well-known, involves bare possessives. The second involves bare determiners. I discuss them in turn in this section. 
Part and parcel of eliding partitives

\subsection{Bare possessives}

Bare possessives are usually assumed to involve NPE: ${ }^{15}$

I prefer Mary's book to John's

Such cases do not seem to involve PartE or ContrA:
a. * I prefer Mary's book to John's of them.
b. ?? I prefer Mary's book to John's one.

There does seem to be a contrasting alternatives requirement for this type of construction to be licit, and so perhaps a variant of the ContrA approach could handle such cases.

However, here I want to challenge the assumption that ellipsis is involved at all in such cases. First consider the following discourse segment:
a. I threw a party last week and specified NO KIDS ALLOWED.
Still, at the very beginning, John brought his three sons.
Then, two hours later, Mary showed up with her three daughters.
b. In the end, I preferred Mary's daughters by far.
c. * In the end, I preferred Mary's by far.

On the basis of the contrast between (41b) and (41c), there seems to be a homogeneity requirement for bare possessives, which does not hold in overt cases. This goes against the meaning parity assumption introduced above. That is, I see no reason why such a requirement should hold under ellipsis. Further, given the possibility of deep anaphora under ellipsis mentioned above, it is unclear why a noun phrase like children couldn't be accommodated in such contexts to satisfy this apparent requirement. ${ }^{16}$

An NPE account would also need to explain why adjectival modifiers cannot be stranded in such cases, given that they can appear overtly:
a. John's beautiful daughter
b. * John's beautiful

15 See for instance Yoshida, Wang \& Potter 2012 for a recent discussion.

16 Another curious fact should be noted here. This homogeneity requirement holds of linguistic antecedents, as seen in (41), but does not hold for pragmatically controlled cases. Consider a context where John walks in the room accompanied by his three sons, and then Mary walks in the room accompanied by her three daughters. In such a context, I can turn to Bill and whisper I prefer Mary's, where what is understood is something like 'I prefer Mary's children'. It thus appears that the grammatically controlled bare possessive is more restricted here than its pragmatically controlled counterpart. 
I believe another argument against an ellipsis account can be made on the basis of a missing ambiguity. Barker (1995) points out cases like the following:

$$
\text { At the kiddie AI fair, I liked the three Japanese children's robots. }
$$

This example can be read as involving three Japanese children and an unspecified plurality of robots which they made. Perhaps not as salient is the reading where there are three robots which were made by an unspecified plurality of Japanese children, perhaps a whole class. Under Barker's analysis, this is cashed out by assuming that both the possessor and the possessee have a variable, which can be bound by the raised quantifier. ${ }^{17}$ With this in mind, consider the following example:

(44) At the kiddie AI fair, I preferred the three Japanese children's robots to the six American children's.

Here, I believe that the bare possessive is unambiguous, involving exactly six American children. If this is the case, it can be accounted for by assuming that no possessee DP has been elided, which would have contained a bindable variable. ${ }^{18}$ But, regardless of the specific treatment given to this ambiguity, the lack of ambiguity in (44) would also run afoul of the meaning parity assumption.

Assuming that cases of bare possessives do not in fact involve ellipsis can prevent us from stipulating a special instance of NPE, or even DPE under the Abney-Barker syntactic analysis.

\subsection{Maximal set anaphora and ellipsis}

Other cases have been pointed out to me which do not clearly involve PartE: ${ }^{19}$

(45) Twenty boys were in the playground when [ten (more) (? of them)] arrived.

(46) A: He didn't see two unicorns.

a. B: No, he saw three _.

b. ? B: No, he saw three of them.

Here it appears that the overt counterparts to the cases involving ellipsis are somewhat degraded. However, even though I am not certain as to what the source of the degradation might be here, I am not convinced that such cases warrant the adoption

17 I am aware that Barker is not so categorical about these cases, but I avoid discussing the complications due to a lack of space. The reader is referred to Barker's work for a more complete picture.

18 Note here that Barker argues in favor of the spec-of-DP syntactic analysis originating from Abney (1987).

19 I am grateful to two anonymous SALT reviewers for pointing out these cases. 
Part and parcel of eliding partitives

of NPE, or $\mathrm{N}^{\prime}$-ellipsis. A possibility here might be to treat the elided partitives as involving plural demonstratives, as they appear more acceptable in such cases. ${ }^{20}$

In any event, I believe that such cases do involve PartE, where the plural pronoun is related not to the reference set of the antecedent, but to the maximal set (Nouwen 2003). Consider the following cases which make this type of reading salient. ${ }^{21}$

(47) Few MPs attended the meeting,

a. but [most__ ] attended the happy hour afterwards.

b. but most of them attended the happy hour afterwards.

I leave as an open question in what contexts plural pronouns can have such readings.

\section{It's eGIVEN!}

Fiengo and May (1994) have famously argued for a principle of structural isomorphy involved in the licensing of ellipsis. There, the core idea is that ellipsis can only be licensed if a 'structurally identical' antecedent to the elided constituent can be found in the relevant discourse context. However, such structural isomorphy clearly does not hold for PartE, given that in none of the cases discussed here was there a partitive phrase antecedent.

Rather, a principle of meaning isomorphy, as argued for by Merchant (2001) would be appropriate here. Merchant suggests that an elided constituent must be eGIVEN in order for the ellipsis to be licensed. This basically requires that an elided constituent, raised to a propositional meaning (by means of existential quantification over unsaturated arguments), both entail and be entailed by its antecedent.

And so, in (48), we need to verify the entailments in (49):

(48) Ten boys walked in the room.

Many of them sat down.

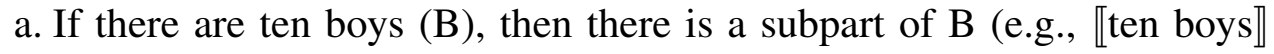
entails F-Clo $(\llbracket$ of them $\rrbracket))$.

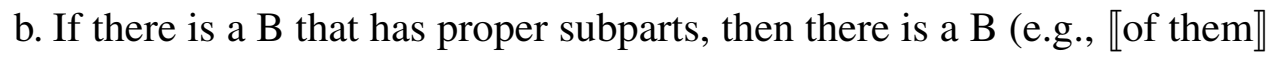

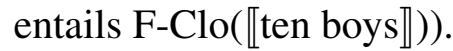

I take these entailments to be trivial here. PartE then favors a meaning isomorphy approach to the licensing of ellipsis, over a structural isomorphy view.

20 I am grateful to Philippe Schlenker for this suggestion.

21 The example is based on one of Nouwen's, originally involving a plural pronoun alone. 


\section{Conclusions}

I have argued that cases of bare determiners, as in (50), involve the ellipsis of a partitive phrase containing a plural pronoun.

(50) Ten boys walked in the room.

Many of them sat down.

To support this view, I have offered arguments from anaphora, the syntax of these expressions, and the interaction between deep anaphora and event anaphora. I have also discussed some possible challenges to this view coming from mass partitives, bare possessives, and maximal set anaphora.

I see this work as a first step towards the strong hypothesis that all cases of crosssentential anaphora, or discourse anaphora, involve not the retrieval of syntactic constituents, but rather the valuation of unsaturated semantic variables over discourse referents, such as those denoted by pronouns.

\section{Appendix: How many Ns can you see?}

Ionin, Matushansky \& Ruys (2011) argue that partitive phrases can either be complements or adjuncts, where a null NP is found in (51):

$$
[D P \text { Two }[N P\langle\text { boys }\rangle[\text { Part } P \text { of }[D P \text { the boys }]]]]
$$

The structure in (51b) is required at least for cases involving numerals. This is due to the privative meaning they assume for numerals such as two. Under their denotation, numerals necessarily combine with semantically singular nouns: ${ }^{22}$

$$
\llbracket\left\{\begin{array}{c}
i k i \\
t w o
\end{array}\right\} \rrbracket=\lambda P_{s g} \cdot\left\{x: \exists Y\left(Y \in \operatorname{part}(x) \&(|Y|=2) \& \forall z\left(z \in Y \rightarrow z \in P_{s g}\right)\right)\right.
$$

a. A predicate $Q$ is of type $P_{s g} \Longleftrightarrow \forall x, y \in Q(x \ngtr y \& y \ngtr x)$

b. $\operatorname{PART}(x)={ }_{\text {def }}\{Z: Z$ is a partition of $x\}$

c. A partition of an aggregate $x$ is a set of aggregates $Z$ such that the join (sum) of all the elements in $\mathrm{Z}$ is equal to $\mathrm{x}(\bigvee Z=x)$ and for any two elements, $w$ and $v$, in $Z$, the meet of those two elements is empty $(w \wedge v=\emptyset)$

Languages such as Turkish, where numerals necessarily combine with singular nouns, is taken as evidence for this denotation, which is generalized to languages such as English:

22 The denotation is taken from Bale, Gagnon \& Khanjian 2011 for notational consistency with the rest of the discussion. 
Part and parcel of eliding partitives
a. iki çocuk
two child
b. * iki çocuk-lar two child-PL

A syntactic structure for the partitive without a null NP would not be compatible with a numeral in English, on the account that a plural predicate is embedded in the partitive.

However, Bale, Gagnon \& Khanjian (2011) have argued for a different denotation for numerals such as $t w o$; a subsective denotation in the spirit of Partee (2010)'s thesis that all modification is restrictive (and not privative). This denotation is perfectly compatible with a structure lacking a null NP in partitives, as it does not require a singular predicate to combine with:

$$
\begin{aligned}
& \left\{\begin{array}{c}
i k i \\
t w o
\end{array}\right\} \rrbracket=\lambda P_{p l} \cdot\left\{x: x \in P_{p l} \& \exists Y(Y \in \operatorname{part}(x) \&(|Y|=2) \& \forall z(z \in Y \rightarrow\right. \\
& \left.\left.z \in \operatorname{MIN}\left(P_{p l}\right)\right)\right)
\end{aligned}
$$

a. A predicate $Q$ is of type $P_{p l} \Longleftrightarrow \forall x, y \in Q(x \oplus y=Q)$

b. $\operatorname{MIN}(P)$ is defined iff

$\forall x, y((x, y \in P \& \neg \exists z(z \in P \&(z \leq y \vee z \leq x))) \rightarrow x \wedge y=0)$. when defined $\operatorname{MIN}(P)=\{x: x \in P \& \neg \exists z(z \leq x)\}$.

Support for this denotation comes from the difference between languages such as English and Turkish in the meaning for the plurally marked and unmarked nouns in predicative position.

Given this subsective denotation for numerals, there is no reason to assume a singular null NP.

\section{References}

Abney, Steven. 1987. The English noun phrase in its sentential aspect: Massachusetts Institute of Technology doctoral dissertation.

Alexiadou, Artemis \& Kirsten Gengel. 2011. Classifiers as morphosyntactic licensors of np ellipsis: English vs. Romance. In Suzi Lima, Kevin Mullin \& Brian Smith (eds.), North East Linguistic Society 39, 15-28.

Bale, Alan, Michaël Gagnon \& Hrayr Khanjian. 2011. Cross-linguistic representations of numerals and number marking. In Nan Li \& David Lutz (eds.), Semantics and Linguistic Theory XX, 582-598.

Barker, Chris. 1995. Possessive Descriptions. Stanford University: CSLI Publications. 
Barker, Chris. 1998. Partitives, double genitives and anti-uniqueness. Natural Language and Linguistic Theory 16(4). 679-717.

Bernstein, Judy B. 1993. Topics in the syntax of nominal structure across Romance: City University of New York doctoral dissertation.

Chisholm, Matt. 2002. Ellipsis in DP. University of California at Santa Cruz MA thesis.

Chomsky, Noam. 1981. Lectures on government and binding. Dordrecht, The Netherlands: Foris Publications.

Corver, Norbert \& Marjo van Koppen. 2009. Let's focus on noun phrase ellipsis. In Groninger Arbeiten zur Germanistischen Linguistiek (GAGL), vol. 48, 3-26.

Corver, Norbert \& Marjo van Koppen. 2011. Np-ellipsis with adjectival remnants: A micro-comparative perspective. Natural Language and Linguistic Theory 29. 371-421.

Elbourne, Paul D. 2005. Situations and Individuals. MIT Press.

Fiengo, Robert \& Robert May. 1994. Indices and identity. Cambridge, Massachusetts: MIT Press.

Halliday, Michael A.K. \& Ruqaiya Hasan. 1976. Cohesion in English. Longman: London.

Hankamer, Jorge \& Ivan Sag. 1976. Deep and surface anaphora. Linguistic Inquiry 7(3). 391-428.

Herschensohn, Julia. 1978. Deep and surface nominalized adjectives in French. Linguistic Inquiry 9(1). 135-137.

Ionin, Tania, Ora Matushansky \& Eddy G. Ruys. 2006. Parts of speech: Towards a unified semantics for partitives. In Christopher Davis, Amy Rose Deal \& Youri Zabbal (eds.), North East Linguistic Society 36, 357-371.

Jackendoff, Ray. 1977. X' Syntax. Cambridge, Massachusetts: MIT Press.

Ladusaw, William A. 1982. Semantic constraints on the English partitive construction. In Daniel P. Flickinger, Marlys Macken \& Nancy Wiegand (eds.), West Coast Conference on Formal Linguistics 1, 231-242. Stanford: Stanford Linguistics Association.

Lobeck, Anne. 1991. The phrase structure of ellipsis. In Susan Rothstein (ed.), Perspectives on Phrase Structure, 81-103. San Diego: Academic Press.

Lobeck, Anne. 1995. Ellipsis: Functional Heads, Licensing and Identification. New York: Oxford University Press.

Matthewson, Lisa. 2001. Quantification and the nature of crosslinguistic variation. Natural Language Semantics 9(1). 145-189.

Merchant, Jason. 2001. The Syntax of Silence: Sluicing, Islands, and the Theory of Ellipsis. Oxford: Oxford University Press.

Neale, Stephen. 1988. Events and "logical form". Linguistics and Philosophy 11(3). 303-321. 
Part and parcel of eliding partitives

Nerbonne, John, Masayo Iida \& William A. Ladusaw. 1989. Running on empty: Null heads in head-driven grammar. In E. Jane Fee \& Katherine Hunt (eds.), West Coast Conference on Formal Linguistics 8, 276-288.

Nouwen, Rick. 2003. Plural Pronominal Anaphora in Context: Utrecht doctoral dissertation.

Panagiotidis, Phoevos. 2003. Empty nouns. Natural Language and Linguistic Theory 12(2). 381-432.

Partee, Barbara. 2010. Formal semantics, lexical semantics, and compositionality: The puzzle of privative adjectives. Philologia 7. 7-19.

Pelletier, Francis Jeffrey. 1975. Non-singular reference: Some preliminaries. Philosophia 5. 451-465.

Sauerland, Uli \& Kazuko Yatsushiro. 2004. A silent noun in partitives. In Keir Moulton \& Matthew Wolf (eds.), North East Linguistic Society, vol. 2 34, 505-516. University of Massachusetts at Amherst: Graduate Linguistic Student Association.

Sleeman, Petra. 1996. Licensing Empty Nouns in French. Holland Institute of Generative Linguistics.

Yoshida, Masaya, Honglei Wang \& David Potter. 2012. Remarks on "gapping” in DP. Linguistic Inquiry 43(3).

\footnotetext{
Michaël R. Gagnon

Department of Linguistics

1401 Marie Mount Hall

University of Maryland

College Park, MD 20742-7505

migagnon@umd.edu
} 